\title{
ARCABOUÇO ESTRUTURAL E ASPECTOS DO TECTONISMO GERADOR E DEFORMADOR DA BACIA BAURU NO ESTADO DE SÃO PAULO
}

\author{
CLÁUDIO RICCOMINI
}

\begin{abstract}
STRUCTURAL FRAMEWORK AND TECTONIC ASPECTS OF THE BAURU BASIN IN THE STATE OF SÃO PAULO, BRAZIL. The Late Cretaceous Bauru Basin, a tectonic unit developed in the central-southern part of the South American Platform, encompasses the sedimentary cover (with asssociated volcanic rocks) that overlies the Neocomian Paraná Flood Volcanics. The depocenter of the basin coincides with the thickest part of the volcanic pile, and this coincidence is interpreted as due to thermal subsidence. With approximately 370,000 $\mathrm{km}^{2}$ in área, the Bauru Basin is roughly elliptical with its major axis oriented NE-SW, and maximum preserved sedimentary fill reaching up to $300 \mathrm{~m}$ in thickness. It is bounded by major tectonic features, namely the Rondonópolis Anteclise to the northwest, the Alto Paranaíba Uplift to the northeast, the Rio Moji-Guaçu, São Carlos-Leme and Ibitinga-Botucatu Lineaments to the east, the Paranapanema Lineament to the southeast, and the Rio Piquiri Lineament to the south. Basin development was continuous between the Santonian and Maastrichtian, and its essentially sandy sedimentary filling represents a single sequence deposited under semi-arid conditions at the border of the basin and desertic conditions within its interior. New tectonic input started in the Maastrichtian, as evidenced in the State of São Paulo by the increasing supply of rudaceous sediments mainly associated with the Paranapanema and Ibitinga-Botucatu Lineaments and by alkaline volcanism along the Rio Moji-Guaçu Lineament, the main tectonic features along the eastern and southeastern borders of the basin, and this volcano-sedimentary episode remains compatible with syn-depositional extension tectonics. Post-sedimentary deformation is marked by two superimposed tectonic regimes of transcurrence, the later probably neotectonic, both related to the geologic megastructure of the State of São Paulo.
\end{abstract}

Keywords: Bauru Basin, Late Cretaceous, tectonics, Paraná Basin, Brazil.

RESUMO A Bacia Bauru, de idade neocretácea, é uma entidade tectônica desenvolvida na porção centro-sul da Plataforma Sul-Americana. Ela engloba a cobertura sedimentar (com rochas vulcânicas associadas) sobreposta aos derrames basálticos neocomianos da Formação Serra Geral, e tem seu depocentro localizado na região onde a pilha vulcânica é mais espessa, razão pela qual vem sendo postulada origem por subsidência termal para a Bacia Bauru. A bacia possui forma aproximadamente elíptica, com eixo maior na direção nordeste, cobre uma extensão de cerca de $370.000 \mathrm{~km}^{2}$ e a espessura máxima preservada de sedimentos atinge cerca de $300 \mathrm{~m}$. Seus limites, essencialmente de natureza tectônica, são desenhados pela Anteclise de Rondonópolis, a noroeste, Soerguimento do Alto Paranaíba, a nordeste, alinhamentos do Rio Moji-Guaçu, São Carlos-Leme e Ibitinga-Botucatu, a leste, do Paranapanema, a sudeste, e do Rio Piquiri, ao sul. O desenvolvimento da Bacia Bauru ocorreu de forma continuada entre o Santoniano e o Maastrichtiano. Seus sedimentos são de natureza essencialmente arenosa e constituem sequência única, depositada sob condiçõos semi-áridas nas bordas a desérticas no interior da bacia. No Maastrichtiano, a atividade tectônica é intensificada, tendo como evidências o incremento no aporte de sedimentos rudáceos, principalmente associado aos alinhamentos do Rio Paranapanema e Ibitinga-Botucatu, e vulcanismo alcalino ao longo do Alinhamento do Rio Moji-Guaçu, feições tectônicas que configuram sua borda leste atual. O tectonismo deformador pós-sedimentar é marcado por dois regimes superpostos, de caráter transcorrente, sendo o último provavelmente neotectônico, e ambos relacionados com a megaestruturação geológica do Estado de São Paulo.

Palavras-chave: Bacia Bauru, Neocretáceo, tectônica, Bacia do Paraná, Brasil.

INTRODUCÃO No início do Cretáceo, após atravessar longo período de relativa estabilidade, a porção sudoeste do paleocontinente Gondwana foi palco do extravasamento de monumental volume de lavas basálticas. Este episódio, que corresponde à Formação Serra Geral, na Bacia do Paraná, no Brasil, e às rochas vulcânicas de Etendeka, na Namíbia, precedeu e acompanhou a ruptura do paleocontinente (Turner et al. 1994), e prosseguiu com o início do espalhamento do assoalho oceânico e a deriva continental, que acarretaram a separação entre a América do Sul e a África e a geração do Atlântico Sul.

Nesse novo quadro tectônico, a porção centro-sul da Plataforma Sul-Americana passa a responder, sucessivamente, aos efeitos da carga representada pelas rochas basálticas -até 1,7 $\mathrm{km}$ de espessura (Almeida 1986), pelo menos 1,6 X $10 \mathrm{~km}$ de área, a julgar pela extensão atualmente preservada (v.g. Renne et al. 1992), e volume da ordem de 7,9 X $10^{5} \mathrm{~km}^{3}$ (Eyles \& Eyles 1993) - à subsidência termal e, posteriormente, ao deslocamento da Placa Sul Americana e sua interação com a Placa de Nazca a oeste (Riccomini 1989, 1995a).

O contexto então existente, de bacia intracratônica (Bacia do Paraná), é cambiado, cedendo lugar para novos tipos de acumulações sedimentares, por vezes extensas, mas de durações relativamente mais efêmeras, em resposta ao novo quadro tectônico.
No Neocretáceo, a Bacia Bauru (Arid 1970, Fulfaro et al. 1982, Fernandes 1992, Coimbra \& Fernandes 1994, Fernandes \& Coimbra 1996) instala-se sobre a área de ocorrência dos derrames Serra Geral, com depocentro coincidente com a maior espessura da pilha vulcânica.

O magmatismo alcalino, cuja fase inicial, no Neocomiano, esteve relacionada ao vulcanismo Serra Geral, é reavivado no Aptiano-Eoceno, com dois máximos em torno de 87-80 e 70-60 Ma (Almeida \& Melo 1981), contemporâneos à sedimentação na Bacia Bauru (Almeida 1986).

O advento do Ciclo Sul-Americano (King 1956), no Neocretáceo a Paleógeno, impõe intensa erosão de amplitude regional. No Estado de São Paulo ele é representado pela Superfície do Japi (Almeida 1964), cujo desenvolvimento acarretou a destruição dos aparelhos vulcânicos mesozóicos e a exposição de diques e outras estruturas subvulcânicas (Almeida 1986), preparando o cenário para as deformações que se seguiram, relacionadas à evolução da Serra do Mar (Almeida 1976).

Esses processos tectônicos, magmáticos, sedimentares e geomorfológicos foram guiados por uma estruturação geral estabelecida já a partir dos estágios finais do vulcanismo Serra Geral, sobretudo na área geográfica onde ocorrera o desenvolvimento da Bacia do Paraná (Riccomini 1995a). 
Dentro deste quadro, a Bacia Bauru no Estado de São Paulo é analisada no presente trabalho quanto ao seu arcabouço estrutural, tectonismo gerador e tectonismo deformador. Adicionalmente, para a região situada ao sul do Rio Tietê, procurou-se caracterizar a evolução dos campos de esforços, seus mecanismos geradores, e suas relações com a geração-deformação das acumulações sedimentares.

Ô estudo regional baseou-se em dados prévios referentes à distribuição geográfica e estratigráfica das unidades sedimentares e vulcânicas da bacia, características sedimentológicas e variações de espessuras dos sedimentos ( $v$.g. Fernandes 1992, Fernandes \& Coimbra 1994), de espessuras das rochas basálticas relacionadas ao magmatismo da Formação Serra Geral (Zalán et al. 1991), e dados geofísicos (Quintas 1995). A caracterização do tectonismo deformador da bacia e a determinação dos paleocampos de tensões esteve fundamentada na análise estrutural de falhas e juntas, procurando-se sempre obter o maior número de dados possível por afloramento.

Os dados estruturais obtidos foram tratados valendo-se dos programas computacionais TRADE (ARTG50), desenvolvido pelo Instituto de Pesquisas Tecnológicas do Estado de São Paulo S.A. (Campanha et al. 1996), e QUICKPLOT, desenvolvido por Van Everdingen \& Van Gool (1990). Todos os diagramas estruturais apresentados correspondem à rede de Schmidt-Lambert, tendo como referência a semi-esfera inferior.

As referências às localidades estudadas, em sua grande maioria, são fornecidas em coordenadas UTM, obtidas com auxílio de GPS (Ensigne, Trimble/Navigation).

A BACIA BAURU A cobertura cretácea sobreposta aos derrames da Formação Serra Geral vem sendo objeto de estudos desde o início deste século. Tantas e tão diversificadas foram as abordagens que permitiram a Fernandes (1992) dividir a evolução dos conhecimentos em quatro fases: pioneira, de caracterização, de mapeamentos litoestratigráfi$c o s$ e atual. Na fase de mapeamentos litoestratigráficos, dentre os trabalhos referidos por este autor, podem ser destacados os de Hasui (1969), Suguio (1973), DAEE (1976), Coimbra (1976), Suguio et al. (1977) e Brandt Neto et al. (1978), dedicados à cartografia e definição das relações estratigráficas desta cobertura, principalmente em SP e MG, mas com extensões para MT e GO, e que encontram na síntese elaborada por Soares et al. (1979) as bases da litoestratigrafia atualmente aceita. Na fase designada de atual estão englobados os estudos de aplicação e revisão das propostas da fase anterior, com a subdivisão de algumas unidades, compreendendo também ensaios de reconstituições paleogeográfica e paleoclimática. Dentre os principais trabalhos desta fase, merecem referência, pela sua abrangência, os de Soares et al. (1980), Almeida et ai. (1980), Barcelos (1984) e Sousa Jr. (1984).

Em investigações mais recentes, Fernandes (1992), Coimbra \& Fernandes (1994) e Fernandes \& Coimbra (1996) enfeixaram a cobertura suprabasáltica na Bacia Bauru, considerada como entidade tectônica distinta da Bacia do Paraná, desenvolvida na porçãoo centro-sul da Plataforma Sul-Americana. Com extensão de cerca de $370.000 \mathrm{~km}$, dos quais $100.000 \mathrm{~km}$ em território paulista, esta bacia possui forma aproximadamente elíptica, com eixo maior na direção nordeste. Seus limites são em grande parte de natureza tectônica e correspondem à Antéclise de Rondonópolis (Coimbra 1991), a noroeste, Soerguimento do Alto Paranaíba (Hasui \& Haralyi 1991), a nordeste, alinhamentos do Rio Moji-Guaçu (Coimbra et al. 1981), São Carlos-Leme e Ibitinga-Botucatu (Riccomini 1995a), a leste, do Paranapanema (Fulfaro 1974), a sudeste, e do Rio Piquiri (Ferreira 1982), ao sul (Fig. 1).

Em âmbito regional, o pacote sedimentar da Bacia Bauru atinge espessura máxima preservada de $300 \mathrm{~m}$. Em sondagem realizada na Estrutura de Piratininga, nos arredores da locali- dade homônima (região de Bauru), foram atravessados $324 \mathrm{~m}$ de sedimentos da Formação Marília do Grupo Bauru (Santos et al. 1980). Hachiro et al. (1994) explicaram essa grande e localizada espessura pela associação dos sedimentos com um graben anelar, disposto concentricamente a uma estrutura de impacto de corpo celeste, que designaram de Astroblema de Piratininga.

A Bacia Bauru, na concepção de Fernandes (1992), Fernandes \& Coimbra $(1992,1996)$ e Coimbra \& Fernandes (1994), compreende sequência sedimentar única (com rochas vulcânicas subordinadas), constituída por depósitos continentais essencialmente arenosos. Segundo esses autores, esta sequência é dividida em dois grupos cronocorrelatos, Caiuá e Bauru (Fig. 1), representativos de um mesmo ambiente, sob clima quente, semi-árido nas bordas e desértico para o interior da bacia. O Grupo Caiuá localiza-se na porção central da Bacia Bauru e compreende os depósitos arenosos interiores de sand sea da Formação Rio Paraná, de periferia da Formação Goio Erê (ausente em São Paulo) e de lençóis de areia e extradunas da Formação Santo Anastácio. Rumo às bordas leste e norte da bacia ocorre o Grupo Bauru, com os depósitos arenosos de sistema fluvial entrelaçado com lagos subordinados das formações Adamantina e Uberaba (esta com contribuição vulcânica e ausente no Estado de São Paulo), e os leques aluviais rudáceos marginais da Formação Marília; estes últimos, no Estado de São Paulo, mostram indicações de paleocorrentes predominantes para oeste e noroeste, indicando aporte de terras altas situadas a leste e sudeste da bacia. As rochas efusivas intercaladas na Formação Adamantina, presentes ao longo do Alinhamento do Rio Moji-Guaçu, apresentam nítido caráter alcalino e são ricas em analcima, tendo sido reunidas por Fernandes \& Coimbra (1996) na unidade designada de Analcimitos Taiúva. Os autores consideram que a sedimentação ocorreu no intervalo Santoniano-Maastrichtiano, tendo como base a idade dos Analcimitos Taiúva (Coutinho et al. 1982) e dos fósseis de vertebrados das formações Adamantina e Marília, além de correlações com a Bacia de Santos.

\section{TECTONISMO GERADOR DA BACIA BAURU}

condicionamento tectônico da deposição dos sedimentos da Bacia Bauru vem sendo enfocado dentro de três linhas interpretativas principais. Foi analisado, inicialmente, no quadro de vinculação dos processos tectono-sedimentares da margem continental atlântica com as áreas situadas no interior da plataforma (Almeida 1976, Soares \& Landim 1976, Fulfaro et al. 1982). Posteriomente, atenção foi dada à influência do movimento de deriva da Placa Sul-Americana e sua interação com as placas vizinhas (Fernandes 1992, Fulfaro \& Barcelos 1993). Em trabalhos mais recentes (Coimbra \& Fernandes 1994, Riccomini 1995a, Fernandes \& Coimbra 1996) é retomada a relação entre a distribuição dos sedimentos e o magmatismo basáltico, originalmente proposta por Northfleet et al. (1969), enquanto Fulfaro \& Perinotto (1996) admitem que a gênese da bacia estaria relacionada aos processos de ruptura do Gondwana e subsequente deriva da placa. Para Riccomini (1995a) a posição da bacia e de seu depocentro, distantes da margem continental, as características de cada processo e os esforços associados, sugerem que esses fatores tiveram interferência direta na Bacia Bauru, tanto na fase geradora como na modificadora. $\mathrm{O}$ tectonismo na margem continental teria atuado na sedimentação, em termos do controle do nível de base regional. A deriva da placa produziria esforços predominantemente compressivos, gerando deformações e deslocamentos comandados por descontinuidades preexistentes, atividade esta que parece mais afeita às estruturas rúpteis que secionam o preenchimento sedimentar. As evidências a favor da existência de tectônica extensional no interior da bacia, a extensão em área da bacia, seu caráter endorreico, a continuidade na sedimentação (constituindo 


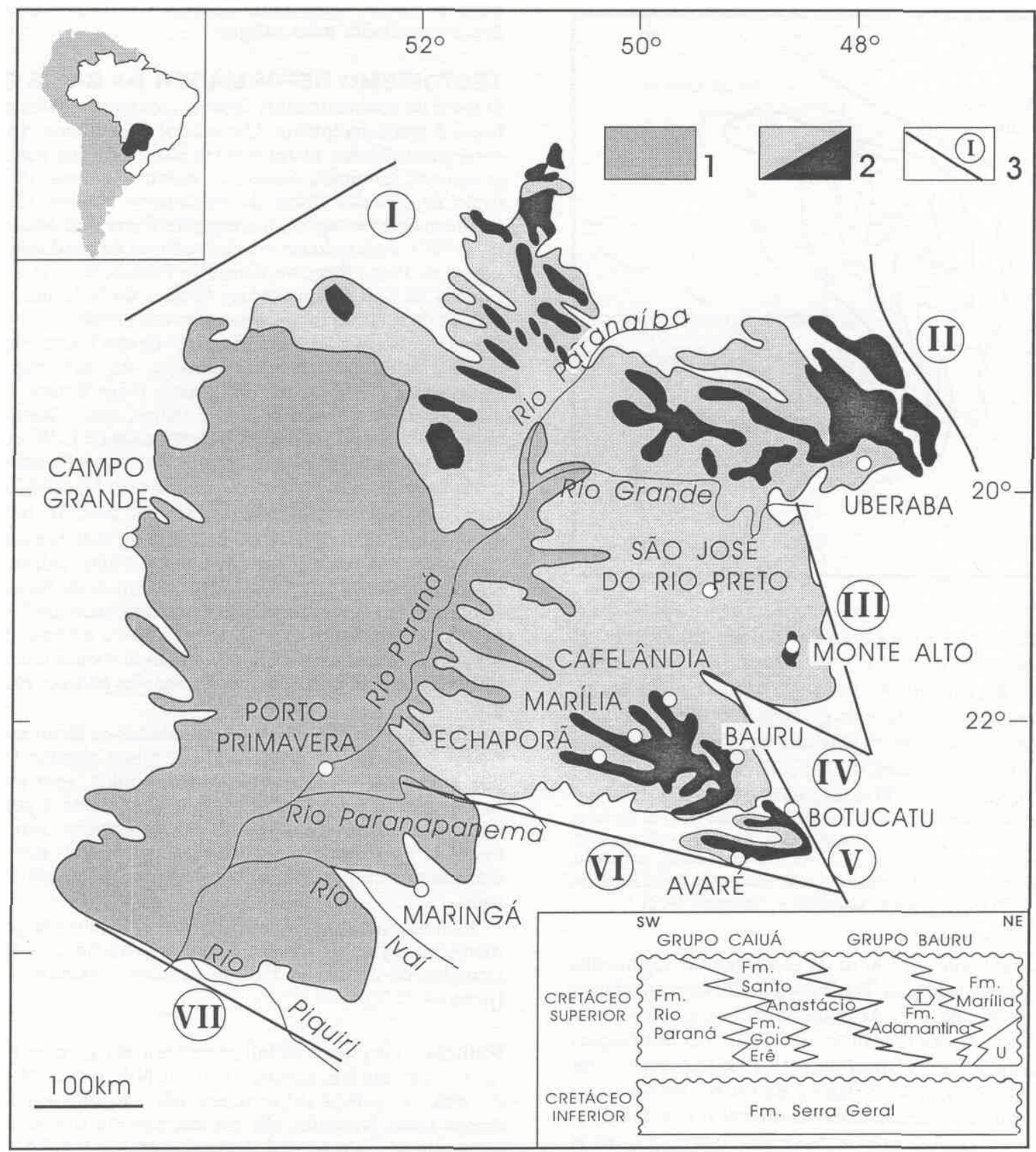

Figura 1 - Distribuição das unidades litoestratigráficas na Bacia Bauru (baseado em Fernandes \& Coimbra 1996): 1. Grupo Caiuá; 2. Grupo Bauru (cinza) e Formação Marília (em preto); 3. Principais feições tectônicas das bordas da Bacia Bauru (I Antéclise de Rondonópolis; II - Soerguimento do Alto Paranaiba; III - Alinhamento do Rio Moji-Guaçu; IV - Alinhamento de São Carlos - Leme; V - Alinhamento de Ibitinga - Botucatu; VI - Alinhamento do Paranapanema; VII - Alinhamento do Rio Piquiri). Quadro menor, canto inferior direito: relações entre as unidades litoestratigráficas da Bacia Bauru (segundo Fernandes \& Coimbra J996). T-Analcimitas Taiúva; U - Formação Uberaba.

Figure 1 - Distribution of lithostratigraphic units in the Bauru Basin (based on Fernandes \& Coimbra 1996): 1. Caiuá Group; 2. Bauru Group (gray) and Marília Formation (black); 3. Main tectonic features of the borders of the Bauru Basin (I - Rondonópolis Antéclise; II - Alto Paranaíba Uplift; III - Rio Moji-Guaçu Lineament; IV - São Carlos - Leme Lineament; V - Ibitinga - Botucatu Lineament; VI - Paranapanema Lineament; VII - Rio Piquiri Lineament). Inset, lower right: stratigraphic relationships within the Bauru Basin (after Fernandes \& Coimbra 1996). T - Taiúva Analcimites; U - Uberaba Formation.

sequência única) e sua relação com a distribuição das lavas basálticas, são indicativos de que a sua formação teria ocorrido através de subsidência lenta e gradual, em resposta à retração do soerguimento crustal (Fulfaro et al. 1982) e arrefecimento de seu substrato (Coimbra \& Fernandes 1994, Fernandes \& Coimbra 1996).

O depocentro da Bacia Bauru localizava-se na porção compreendida pelo Pontal do Paranapanema e noroeste do
Paraná, em correspondência às maiores espessuras da pilha de lavas. Para esta região, Quintas (1995) determinou valor máximo de atenuação, relacionado ao vulcanismo basáltico, da ordem de 1,25, o que implicaria em decréscimo da topografia de cerca de $500 \mathrm{~m}$, sendo este valor em parte compensado pelo aumento volumétrico resultante da fusão dos magmas. Se considerado ainda o incremento resultante da subsidência termal, a profundidade da depressão então gerada 


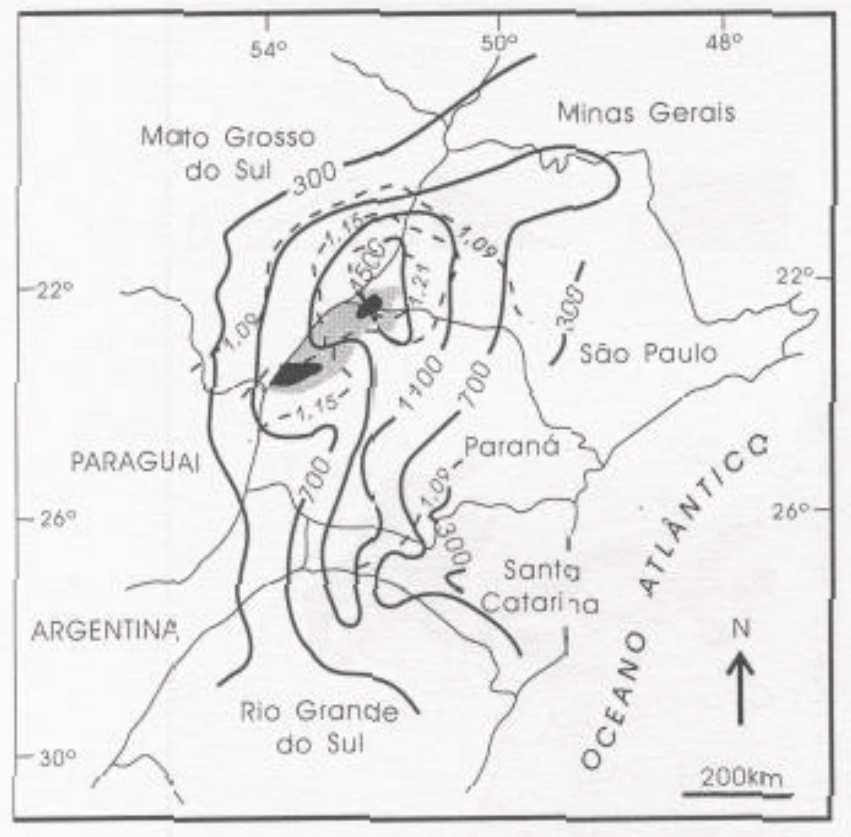

Figura 2 - Relações entre a espessura das rochas magmáticas da Formação Serra Geral (linhas contínuas, espessuras em metros, segundo Zalán et al. 1991), isoatenuações relacionadas ao vulcanismo basáltico (linhas pontilhadas, valores adimensionais, segundo Quintas 1995) e espessuras mínimas preservadas dos sedimentos da Bacia Bauru (em cinza para espessuras entre 100 e $200 \mathrm{~m}$ e em preto para espessuras superiores a $200 \mathrm{~m}$, segundo Fernandes 1992). Figure 2 - Relationships among the thickness of magmatic rocks of the Serra Geral Formation (heavy lines, thickness in meters, according to Zalán et al. 1991), isoattenuations related to basaltic volcanism (according to Quintas 1995) and minimum preserved thickness of sediments in the Bauru Basin (in gray, 100-200 m; in black, > $200 \mathrm{~m}$, according to Fernandes 1992).

seria compatível com os $300 \mathrm{~m}$ de espessura de sedimentos preservados naquela região. Na Figura 2 são apresentadas as relações entre a espessura da pilha de rochas vulcânicas da Formação Serra Geral (Zalán et al, 1991), as atenuações relacionadas a este vulcanismo (Quintas, 1995) e as espessuras mínimas dos sedimentos da Bacia Bauru na região oeste paulista (Pontal do Paranapanema) e noroeste do Paraná (Fernandes, 1992), notando-se evidente correspondência entre os maiores valores dos três parâmetros e a nítida disposição alongada do embaciamento segundo a direção NE. Tais fatos permitem postular o modelo de subsidência termal (v.g. Chang et al. 1990) para a instalação da Bacia Bauru.

A existência de pulsos tectônicos durante a sedimentação é atestada: a) pela presença de sismitos em depósitos eólicos do Grupo Caiuá, na região do Pontal do Paranapanema, SP (Coimbra et al. 1992); b) pelas ocorrências de arenitos silicificados por processos hidrotermais penecontemporâneos à sedimentação, alinhados segundo a direção NE, presentes nesta mesma região e na porção noroeste do Paraná (Fernandes et al. 1993), e concordantes com direções de fraturas ali presentes; c) pela distribuição dos leques aluviais rudáceos polimíticos da Formação Marília, relacionados aos alinhamentos do Rio Paranapanema, Ibitinga-Botucatu e do Rio Moji-Guaçu, contendo seixos de rochas do embasamento pré-cambriano (gnaisses, granitos, anfibolitos, quartzitos) situadas nos flancos leste e sudeste da bacia; e d) pela relação dos focos de magmatismo alcalino analcimítico com o Alinhamento do Rio Moji-Guaçu. Em todos os casos, parece ser claro o vínculo com fenômenos de reativação ao longo de descontinuidades mais antigas.

\section{TECTONISMO DEFORMADOR DA BACIA BAURU}

O nível de conhecimentos sobre o tectonismo deformador da bacia é ainda incipiente. Os estudos específicos, voltados à caracterização das estruturas rúpteis e de seus mecanismos geradores, são ainda escassos e restritos às áreas de implantação de grandes obras de engenharia. Dentre estes, pela natureza da abordagem, merece referência o de Magalhães et ai. (1992), realizado no maciço rochoso da fundação da Barragem de Porto Primavera, no Rio Paraná, na divisa entre os estados de São Paulo e Mato Grosso do Sul, que incluiu a análise de juntas e falhas presentes nos arenitos da Formação Caiuá, ou Formação Rio Paraná do Grupo Caiuá, segundo a divisão estratigráfica aqui adotada. As descontinuidades cadastradas nos arenitos, em grande parte fraturas, mas incluindo um pequeno número de falhas, apresentaram orientação preferencial segundo ENE, próxima de E-W, com mergulhos subverticais. $\mathrm{O}$ conjunto de estruturas foi relacionado a um único evento tectônico, posterior ao Neocretáceo, cujo regime de deformação teria ai próximo de E-W, horizontal, a2 próximo da vertical, e 03 próximo de $\mathrm{N}-\mathrm{S}$, horizontal.

Em levantamentos executados na região balizada pelas cidades de São Manuel, Cafelândia e Echaporã, foram cadastradas falhas e juntas seccionando os depósitos das formações Marília e Adamantina; o caráter tectônico e pós-sedimentar dessas estruturas é atestado por afetarem rochas inteiramente litificadas e pela persistência em área dos padrões reconhecidos.

No mapa da figura 3 estão assinalados os locais estudados (letras A a O) e plotados os dados de juntas obtidos. Optou-se por representá-los unicamente pêlos pólos, sem curvas de isofreqüência, tendo em vista que geralmente é pequeno o número de dados passíveis de serem obtidos. Em um dos locais (C) encontra-se representada na figura, por círculos máximos, uma população de falhas de caráter não determinado.

Falhas com estrias ocorrem de forma localizada, principalmente na região de Marília-Echaporã. Na figura 4 são apresentados os dados de falhas (círculos máximos) e estrias (pontos).

Falhas Os planos de falhas apresentam direções predominantes segundo NE, secundariamente NW, NNE e NNW (Fig. 4), têm mergulhos subverticais, não são preenchidos, e as estrias neles presentes são em sua maioria subhorizontais e correspondem a marcas de arrasto entre superfícies. Os rejeitos horizontais verificados são de magnitude centimétrica a métrica.

Para cerca de dois terços da população de falhas foi possível definir o sentido de movimento. Em alguns poucos casos pode ser observada a superposição de estrias em um mesmo plano. Embora o volume de dados seja pequeno e as relações de superposição verificadas pouco numerosas, os dados puderam ser ordenados cronologicamente, sendo tratados pelo método gráfico dos diedros retos (Angelier \& Mechler 1977). Para o conjunto mais antigo, o eixo de tensão principal máxima, ai, orienta-se segundo E-W, horizontal, com pequenas variações para ENE e WSW, o eixo de tensão principal mínima, a3, orienta-se segundo N-S, horizontal, com pequenas variações para NNW e NNE, e o eixo intermediário, $\sigma 2$, é vertical (Fig. 5A). O conjunto mais novo possui ai de direção N-S, horizontal, com pequenas variações para NNW e NNE, $\sigma 3$ de direção E-W, horizontal, com oscilações para ENE e WSW, e $\sigma 2$ vertical (Fig. 5B). Para ambos os conjuntos, a verticalidade das superfícies de falhas e a posição subhorizontal das estrias indicam a vigência de regime transcorrente. 


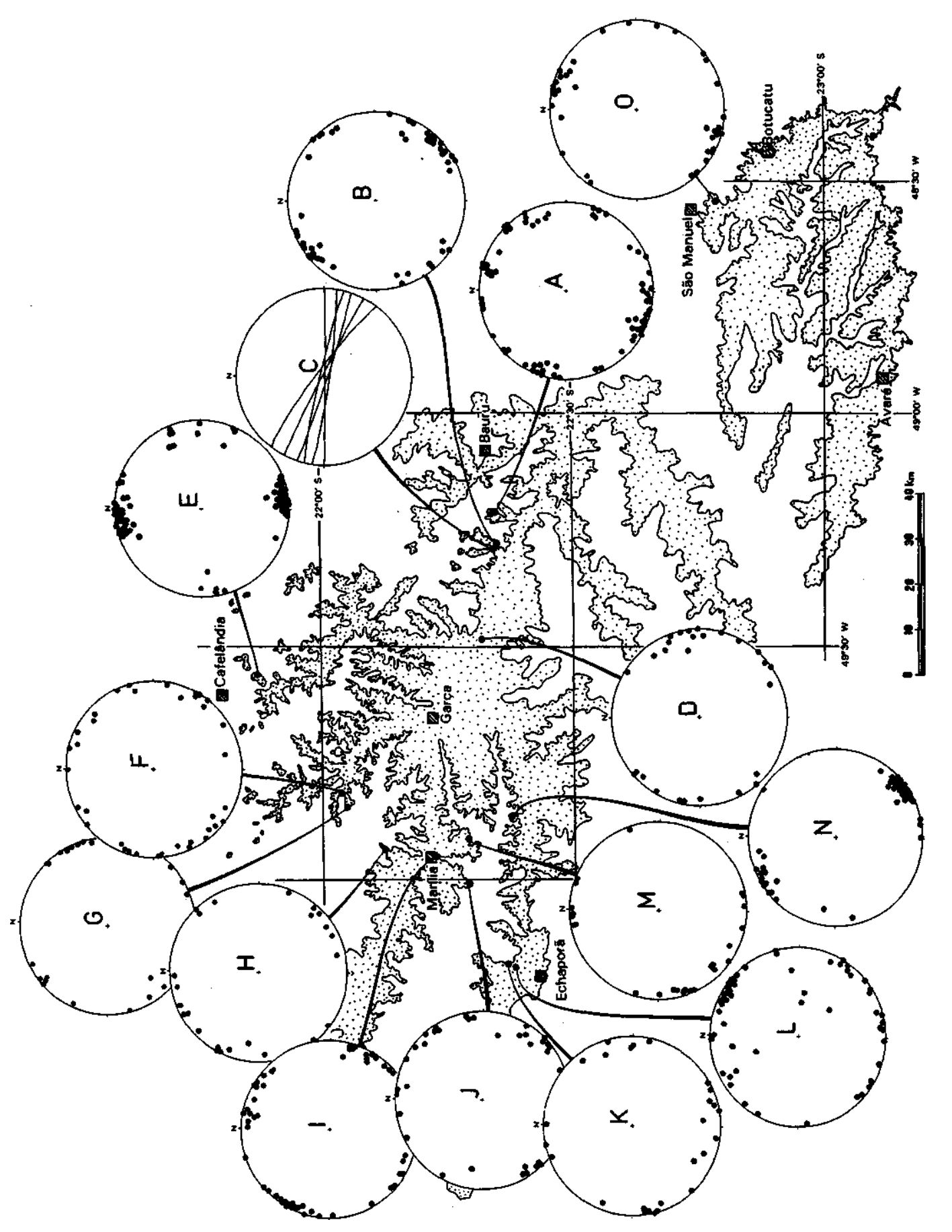

$5=+5$

इ तु

की

กิ่

4I"

$5 \geq \pi$

सेखि

षंड 0 ह

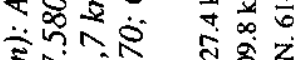

जर北

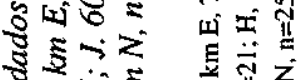

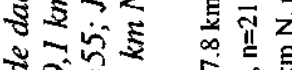

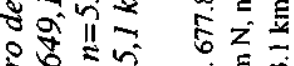

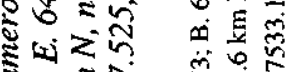

为的

iा

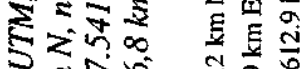

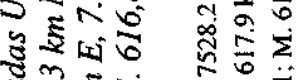

$=5 z$

केष

8 성

声云文

पบ 0 ती

焉

落

कात

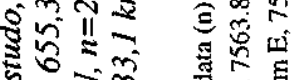

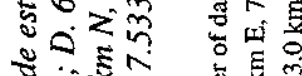

है

उुज

8.

$\sum_{-\infty} \sum^{2}$

$\$ g \bar{m}$

$5 \infty^{\circ}$ II $\sum \frac{1}{2}$

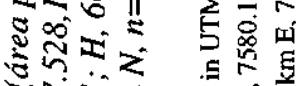

क人त्र

$\pm=n$ 要要

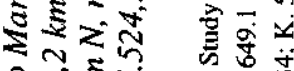

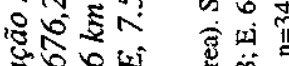

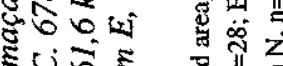

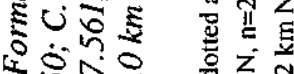

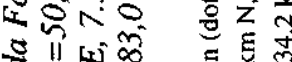

8 पा

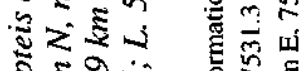

ํํㅇ की

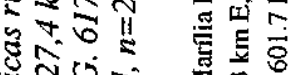

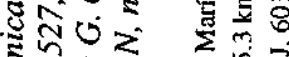

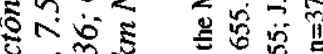

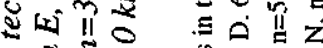

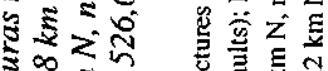

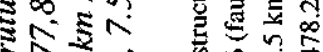

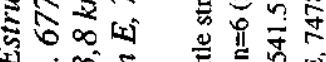

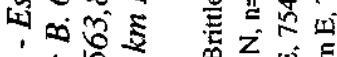

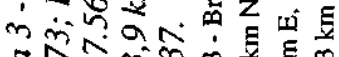

र八ले के

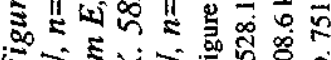



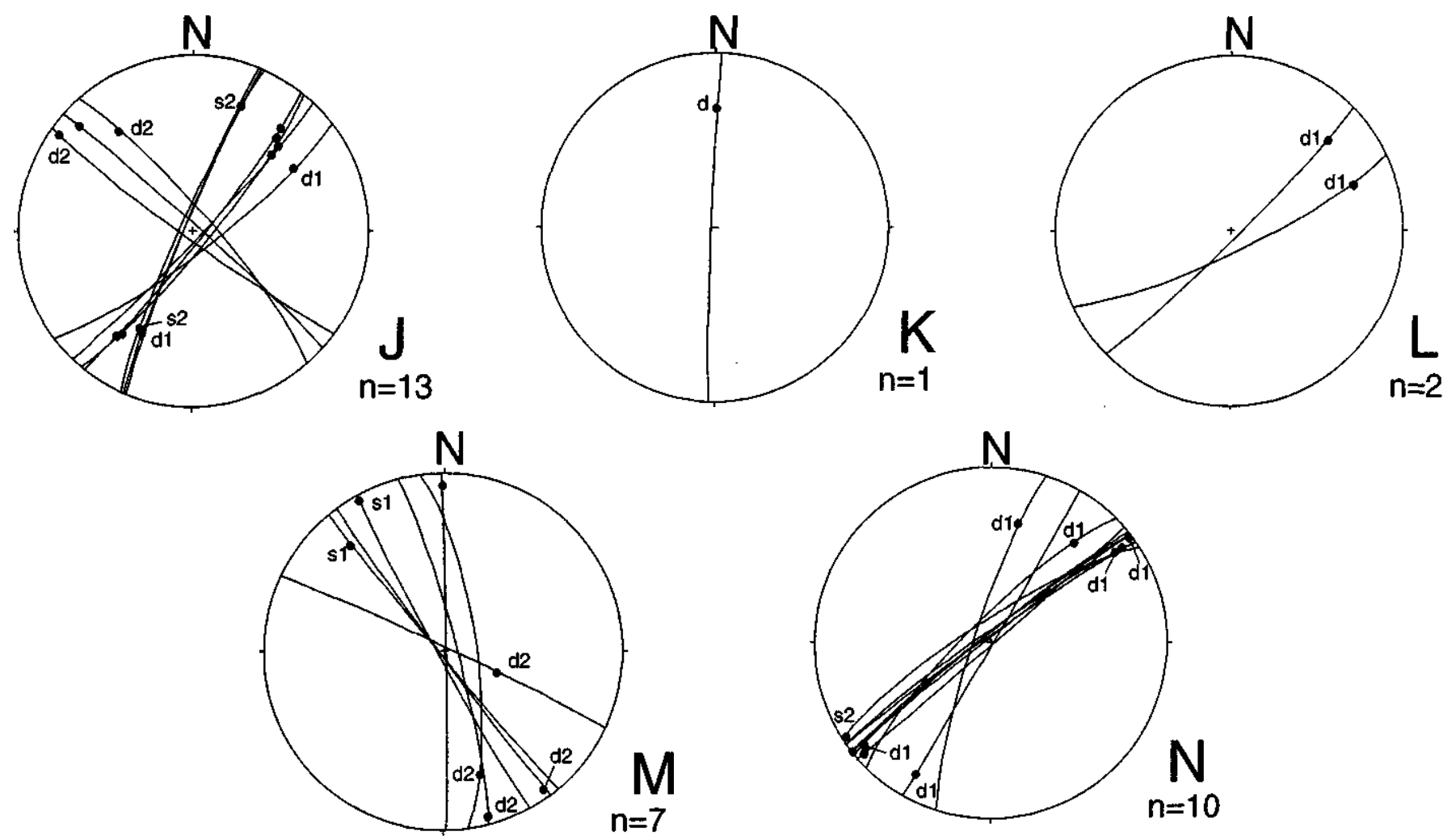

Figura 4 - Superficies de falhas com estrias de atrito obtidas na Formação Marília (n = número de dados), com a indicação do movimento (d - dextral, $s$ - sinistral) e cronologia relativa (números l e 2 para as falhas mais antigas e mais jovens, respectivamente) onde determinado. As letras maiúsculas correspondem aos locais da Figura 3.

Figure 4 - Fault data with respective striae in the Marilia Formation $(\mathrm{n}=$ number of data), with indicated sense of movement ( $\mathrm{d}$ - right-lateral, $\mathrm{s}$ - left-lateral) and the relative chronology (numbers 1 and 2 for the older and younger faults, respectively), where determined. Capital letters correspond to sites indicated in Figure 3.
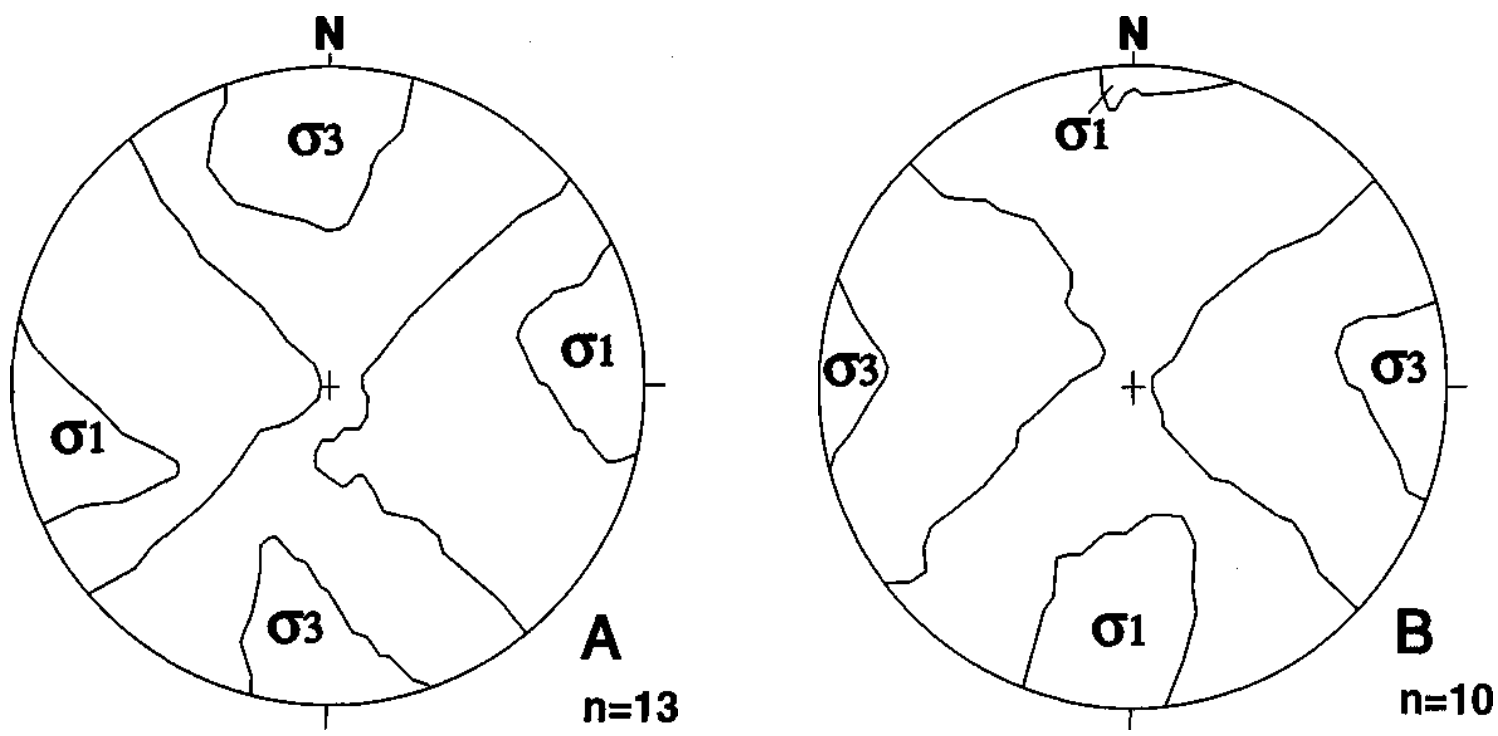

Figura 5 - Resultado da aplicação do método gráfico de Angelier \& Mechler (1977) às populações de falhas mais antigas (A) e mais jovens (B), sendo $n=$ número de dados. Os campos para ole $\sigma 3$ estão delimitados por isolinhas de 98 e $0 \%$, respectivamente. Figure 5 - Result of application of the method of Angelier \& Mechler (1977) for the older (A) and younger (B) fault populatios ( $\mathrm{n}=$ number of data). The fields for $\sigma 1$ and $\sigma 3$ are delimitated by isolines of 98 and $0 \%$, respectively. 
Juntas As juntas são subverticais e constituem três classes principais (Fig. 3):

a) famílias conjugadas ortogonais entre si (locais $A, B, I, J$, $K$ e $M$ ), onde as direções NE e NW, com pequenas variações, são as mais frequentes; correspondem a famílias de juntas conjugadas ortogonais (Caputo 1995);

b) famílias conjugadas formando ângulos agudos que variam entre 37 e $69^{\circ}$ (locais $D, F, G, H, L$ e O ); as de menor ângulo agudo (locais L e 0 ) correspondem à juntas híbridas (Dunne \& Hancock 1994) e têm suas bissetrizes orientadas segundo a direção E-W (WNW-ESE a ENE-WSW), permitindo deduzir que $\sigma 1$ é horizontal, nesta direção, $\sigma 2$ é vertical e a3 é horizontal orientado segundo a direção aproximada N-S; as famílias que formam maior ângulo agudo entre elas (locais $D, F, G$ e $H$ ) correspondem ajuntas (fraturas) de cisalhamento (Dunne \& Hancock 1994), com bissetrizes agudas tendendo para N-S (NNW a NNE), permitindo situar $\sigma 1$, horizontal, nesta direção, $\sigma 2$ na direção vertical e $\sigma 3$, horizontal, segundo E-W.

c) populações com absoluta predominância de uma direção sobre outra ortogonal (locais $E$ e N), constituindo prováveis famílias de juntas de extensão (v.g. Pollard \& Aydin 1988); as direções predominantes são ENE a E-W, exibindo, localmente, superficies "penadas" (Engelder 1987), com eixos das plumas subhorizontais, correspondendo à direção de $\sigma 1$, tendo $\sigma 3$ horizontal, na direção ortogonal às superfícies, e $\sigma 2$ vertical; as direções secundárias, não sistemáticas, parecem representar cross joints (Hancock \& Engelder 1989).

As observações de campo e a análise das estruturas mostram que as atitudes das falhas são em parte coincidentes com as de juntas preexistentes, podendo, ao menos em parte, representar reativações destas. Os eixos de tensões obtidos para as falhas mais antigas (com $\sigma 1, \mathrm{E}-\mathrm{W} /$ horizontal, a2 vertical e a3, N-S/horizontal) são concordantes com aqueles da região de Porto Primavera (Magalhães et al. 1992), o que poderia sugerir a vigência do mesmo campo de tensões a nível regional. Por outro lado, os eixos de tensões obtidos para a população de falhas mais jovens (com $\sigma 1, \mathrm{~N}-\mathrm{S} /$ horizontal, $\sigma 2$ vertical e $\sigma 3, \mathrm{E}-\mathrm{W} /$ horizontal) possuem orientação compatível com as deformações originadas por falhas transcorrentes e normais que secionam depósitos quaternários de terraços fluviais, stone-lines e colúvios, sobrepostos às rochas sedimentares da Bacia Bauru na área em estudo, indicando vínculo com a atividade neotectônica da região (Riccomini 1995a).

\section{RELAÇÕES COM AS ESTRUTURAS DO EM-}

BASAMENTO Na área geográfica da Bacia do Paraná, no Estado de São Paulo, são reconhecidos alinhamentos estruturais de direções WNW, NW e NNW, configurando um padrão em blocos romboidais (Fig. 6). Eles foram atuantes na distribuição das unidades sedimentares (Amaral 1977), dos focos de magmatismo alcalino e de altos estruturais, feições essas evidentes mesmo numa observação inicial dos mapas geológicos do Estado de São Paulo em 1:1.000.000 (IGG 1974) e 1:500.000 (Bistrichi et al. 1981).

O Alinhamento do Rio Paranapanema (Fulfaro 1974) é pontilhado pelos altos estruturais de Jacarezinho (PR), Neblina, Jacu, Carlota Prenz, Rio Grande, Jacutinga e Guarda (SP), além de abrigar a intrusão de Ipanema. O Alinhamento do Rio Moji-Guaçu (Coimbra et al. 1981) engloba as intrusões de Ipanema, Varnhagem e Salto de Pirapora; no seu encontro com o Alinhamento de Cabo Frio (Sadowski \& Dias Neto 1981, Almeida 1991) ocorrem os analcimitos de Aparecida do Monte Alto, Piranji, Taiúva e a intrusão de Jaboticabal e, nas proximidades de seu cruzamento com o Alinhamento Estrutural do Rio Tietê (Coimbra et al. 1977), é sítio dos altos estruturais de Pitanga, Artemis, Pau d'Alho e Jibóia. Outros alinhamentos, aparentemente de menor expressão, podem também ser delineados, dentre estes o de Ribeirão Preto Campinas, que parece ter exercido certo controle na distribuição dos sedimentos rudáceos da região de Franca e Pedregulho e das soleiras de diabásio nas unidades paleozóicas, estas na área correspondente ao Soerguimento de MojiGuaçu (Hasui et al. 1982), e o de Rifaina - São João da Boa Vista, que delimita a extensão nordeste da área de ocorrência dos sedimentos paleozóicos da Bacia do Paraná.

A borda oriental da Bacia Bauru, no Estado de São Paulo, é atualmente delimitada pelos alinhamentos estruturais do Rio Paranapanema, Ibitinga - Botucatu, São Carlos - Leme e do Rio Moji-Guaçu. Não é improvável, entretanto, que represente aproximadamente o limite leste de sua extensão original, a julgar pela distribuição de fácies rudáceas da Formação Marília e a presença de rochas alcalinas intercaladas nos sedimentos ao longo desta borda.

O arranjo da borda oriental da Bacia Bauru, a distribuição da Formação Itaqueri e as reentrâncias na atual área de ocorrência dos magmatitos Serra Geral, sugerem movimentações de componentes sinistrai e dextral, respectivamente ao longo dos alinhamentos de direção NNW e WNW. Os alinhamentos de direção WNW podem ser relacionadas com estruturas sintéticas $(R)$ e os de direção NNW com estruturas antitéticas (R') de Riedel (1929), em um modelo transcorrente com binário dextral de orientação próxima de E-W (Fig. 6). Neste mesmo modelo, os alinhamentos de direção NW estariam na direção do esforço principal máximo, $\sigma l$, e corresponderiam a direções de tração (T) (v.g. Sadowski 1984). Embora existam evidências diretas desses deslocamentos, há também indicações, igualmente diretas, de movimentações opostas, sugestivas de processos de reativação. As ocorrências de manifestações alcalinas do Eocretáceo (Ipanema) e Neocretáceo (Taiủva, Jaboticabal) são elementos adicionais em favor da existência de atividade tectônica recorrente ao longo desses alinhamentos.

Esta megaestruturação posterior ao magmatismo Serra Geral é também verificada a nível das estruturas em escala mesoscópica (falhas e juntas estudadas em afloramentos), tanto em termos geométricos (arranjo espacial) como cinemáticos, relacionadas ao tectonismo deformador póssedimentar. Estas estruturas podem ser interpretadas como resultantes de dois regimes transcorrentes.

CONSIDERAÇÕES FINAIS Os dados disponíveis acercado Neocretáceo no Estado de São Paulo e áreas vizinhas parecem indicar a permanência dos esforços relacionados a um binário dextral de orientação geral E-W, vigente desde a fase tardia do episódio Serra Geral (Riccomini 1995a, b); a ação desse binário teria promovido os deslocamentos ao longo de alinhamentos estruturais de expressão regional, com deformações mais intensas nas porções central e oriental do estado, como bem registrado no Maciço Alcalino de Cananéia, do Santoniano -Campaniano (Riccomini 1995b). Na região oeste do estado, o campo de tensões regional teria sido sobrepujado pela subsidência associada ao grande volume de rochas basálticas, ensejando a instalação da Bacia Bauru, desenvolvida no intervalo de tempo compreendido entre o Santoniano e o Maastrichtiano.

A intensificação do tectonismo de caráter rúptil na Bacia Bauru é evidenciada pelo incremento no aporte de sedimentos rudáceos (Formação Marília) e também pelo vulcanismo alcalino extrusivo, no Maastrichtiano, relacionados à atividade tectônica dos alinhamentos que configuram a sua borda leste atual.

O tectonismo deformador sucedeu-se ao preenchimento sedimentar da bacia, deixando registradas estruturas, como falhas e juntas, que podem ser interpretadas como resultantes de dois regimes transcorrentes, inicialmente com $\sigma 1$, E-W/horizontal, $\sigma 2$ vertical e $\sigma 3, \mathrm{~N}-\mathrm{S} /$ horizontal e, posterior- 


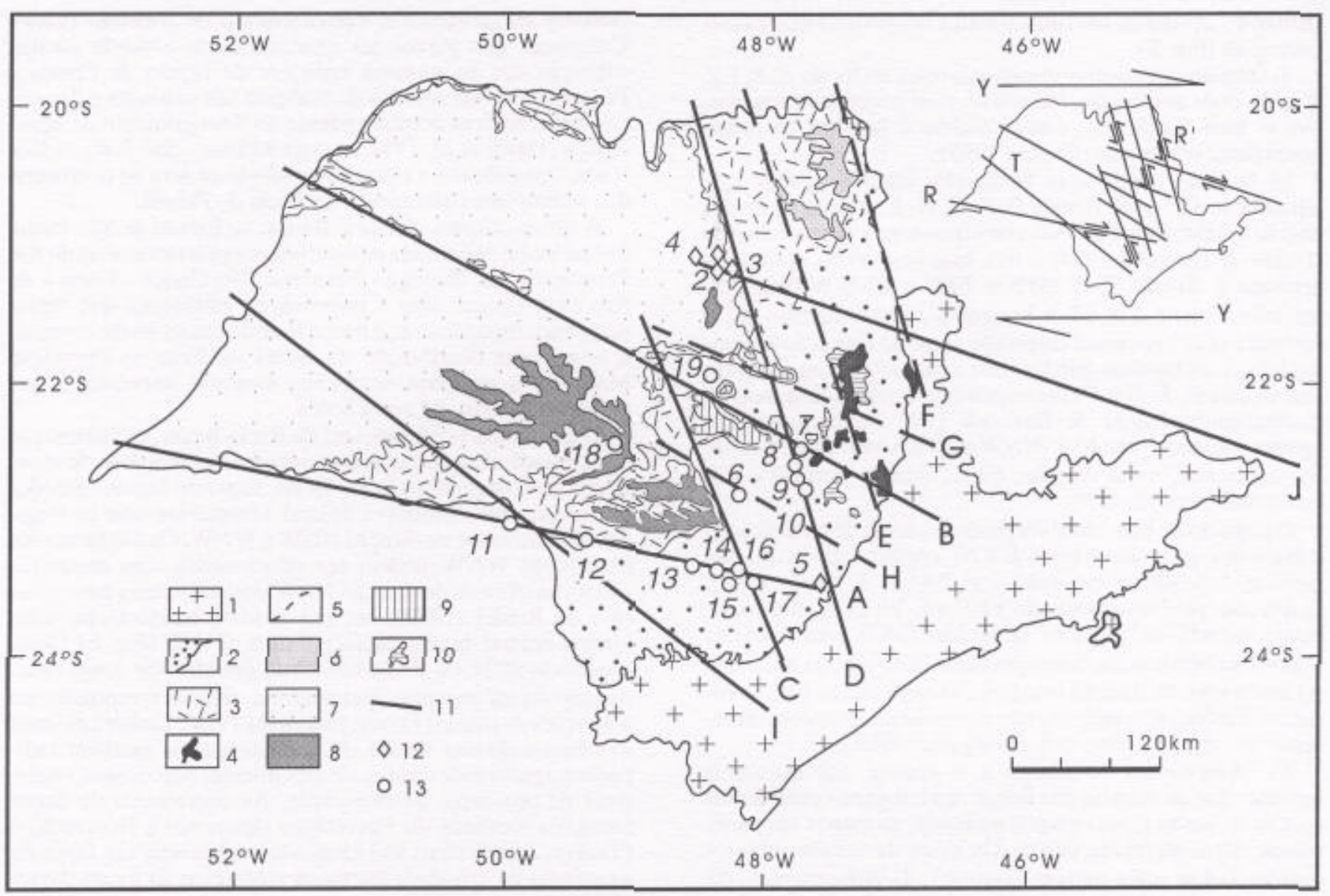

Figura 6 - Principais alinhamentos estruturais da área geográfica da Bacia do Paraná no Estado de São Paulo (segundo Riccomini 1995a, modificado). 1. substrato pré-cambriano, em parte recoberto por sedimentos cenozóicos; 2. terrenos paleozóicos e mesozóicos da Bacia do Paraná, subjacentes aos derrames superiores da Formação Serra Geral; 3. rochas vulcânicas da Formação Serra Geral; 4. sills de diabásio; 5. contato aproximado entre 2 e 3; 6. depósitos rudáceos da região de Franca-Pedregulho; 7. grupos Caiuá e Bauru, não diferenciados; 8. Formação Marília, Grupo Bauru; 9. Formação Iïtaqueri; 10. Formação Rio Claro e depósitos correlatas; 11. alinhamentos estruturais (A - Rio Paranapanema; B - Tietê; C - Ibitinga Botucatu; D - Rio Moji-Guaçu; E - Ribeirão Preto - Campinas; F - Rifaina - São João da Boa Vista; G - São Carlos - Leme; H Barra Bonita - Itu; I - Guapiara; J - Cabo Frio); 12. manifestações alcalinas (1 - Taiúva; 2 - Aparecida do Monte Alto; 3 Jaboticabal; 4 - Piranji; 5 - Ipanema/Araçoiaba da Serra); 13. altos estruturais (6 - Domo de Anhembi-Piapara; 7 - Estrutura de Pitanga; 8 - Domo de Artemis; 9 - Horst de Pau d'Alho; 10 - Domo de Jibóia; 11 - Domo de Jacarezinho; 12 - Domo da Neblina; 13 - Domo de Jacu; 14 - Estrutura Dômica de Carlota Prenz; 15 - Domo de Rio Grande; 16 - Domo de Jacutinga; 17 - Domo de Guarda; 18 - Astroblema de Piratininga; 19 - Domo de Jacaré-Guaçu). Mapa menor: relações dos alinhamentos comfraturas sintéticas $(R)$, antitéticas $\left(R^{\prime}\right)$, de tração $(T)$, em relação a um binário transcorrente dextral de direção $E$-W(Y). Figure 6 - Main structural lineaments in the region of the Paraná Basin, São Paulo. 1. Precambrian basement, partly covered by Cenozoic sediments; 2 . Paleozoic and Mesozoic terranes of the Paraná Basin beneath the upper lava-flows of the Serra Geral Formation; 3. volcanic rocks of the Serra Geral Formation; 4. diabase sills; 5. approximate boundary between 2 and 3;6. rudaceous deposits in the Franca - Pedregulho region; 7. Caiuá and Bauru groups, undifferentiated; 8. Marília Formation, Bauru Group; 9. itaqueri Formation; 10. Rio Claro Formation and correlative deposits; 11. structural lineaments (A - Rio Paranapanema; B - Tietê; C - Ibitinga - Botucatu; D - Rio Moji-Guaçu; E - Ribeirão Preto - Campinas; F - Rifaina - São João da Boa Vista; G - São Carlos - Leme; H - Barra Bonita - Itu; I Guapiara; J - Cabo Frio); 12. alkaline rocks (1 - Taiúva; 2 - Aparecida do Monte Alto; 3 -Jaboticabal; 4 - Piranji; 5 - Ipanema/Araçoiaba da Serra); 13. structural highs (6 - Anhembi-Piapara Dome; 7 - Pitanga Structural High; 8 - Artemis Dome; 9 - Pau d'Alho Horst; 10 - Jibóia Dome; 11 - Jacarezinho Dome; 12 - Neblina Dome; 13-Jacu Dome; 14-Carlota Prenz Dome; 15 - Rio Grande Dome; 16-Jacutinga Dome; 17-Guarda Dome; 18 - Piratininga Astrobleme; 19-Jacaré-Guaçu Dome). Inset, upper right: relationship of structures according to the Riedel model with a E-W right-lateral binary (Y) (R - synthetic fractures; R' - antithetic fractures; $\mathrm{T}$ - tension fractures).

mente, com $\sigma 1, \mathrm{~N}-\mathrm{S} /$ horizontal, $\sigma 2$ vertical e $\sigma 3$, E-W horizontal, correlacionáveis à megaestruturação geológica do Estado de São Paulo, sendo o último provavelmente vinculado à atividade neotectônica regional.

Agradecimentos $\mathrm{O}$ autor externa seus agradecimentos ao Prof. Dr. Luiz José Homem D'el-Rey Silva (IG-UnB), pelos valiosos comentários e sugestões apresentadas, e à Fundação de Amparo à Pesquisa do Estado de São Paulo (FAPESP) e Conselho Nacional de Desenvolvimento Científico e Tecnológico $(\mathrm{CNPq})$ pelo financiamento de parte da pesquisa que resultou neste artigo; ao Prof. Dr. Thomas R. Fairchild (IG-USP) pela revisão do abstract e à Thelma Samara (IG-USP) pela confecção de parte das figuras. 


\section{REFERENCIAS}

Almeida, F.F.M. 1964. Fundamentos geológicos do relevo paulista. Bol. IGG 41:167-262

Almeida, F.F.M. 1976. The system of continental rifts bordering the Santos Basin, Brazil. An. Acad. bras. Ci., 48(suplemento):15-26.

Almeida, F.F.M. 1986. Distribuição regional e relações tectônicas do magmatismo pós-paleozóico no Brasil. Rev. Bras. Geoc., 16:325-349.

Almeida, F.F.M. 1991. O Alinhamento Magmático de Cabo Frio. In: SIMPOSIO DE GEOLOGIA DO SUDESTE, 2, São Paulo, 1991. Atas... São Paulo, SBG/SP. p.423-428.

Almeida, F.F.M. \& Melo, M.S. 1981. A Bacia do Paraná e o vulcanismo mesozóico. In: Bistrichi, C.A; Carneiro, C.D.R; Dantas, A.S.L.; Ponçano, W.L.; Campanha, G.A.C.; Nagata, N.; Almeida, M.A.; Stein, D.P.; Melo, M.S.; Cremonini, O.A. Mapa geológico do Estado de São Paulo. Escala J:500.000. São Paulo, SICCT. v.l,'126p.

Almeida, M.A.; Stein, D.P.; Melo, M.S.; Bistrichi C.A.; Ponçano, W.L.; Hasui, Y.; Almeida, F.F.M. 1980. Geologia do oeste paulista e áreas fronteiriças dos estados de Mato Grosso do Sul e Paraná. In: CONGRESSO BRASILEIRO DE GEOLOGIA, 31, Balneário de Camboriú, 1980. Anais... Balneário de Camboriú, SBG. v.5, p.2.799-2.812.

Amaral, G. 1977. Padrões fotogeológicos dos litofácies da Formação Bauru no Estado de São Paulo, como observados em imagens LANDSAT. In: SIMPÓSIO DE GEOLOGIA REGIONAL, 1, São Paulo, 1977. Atas... São Paulo, SBG. p.439-499.

Angelier, J. \& Melcher, P. 1977. Sur une méthode graphique de recherche des constraintes principales également utilisable en tectonique et en seismologie: Ia méthode des dièdres droits. Bull. Soe. Géol. France, 7:1309-1318.

Arid, F.M. 1970. A Formação Bauru na região norte-ocidental do Estado de São Paulo. In: CONGRESSO BRASILEIRO DE GEOLOGIA, 24 Brasília, 1970. Resumos das Conferências e Comunicações... Brasília, SBG. p.373-377.

Barcelos, J.H. 1984. Reconstrução paleogeográfica da sedimentação do Grupo Bauru baseada na sua redefinição estratigráfica parcial em território paulista e no estudo preliminar fora do Estado de São Paulo. Rio Claro, 109p. (Tese de Livre-Docência, Instituto de Geociências e Ciências Exalas da Universidade Estadual Paulista).

Bistrichi, C.A; Carneiro, C.D.R; Dantas, A.S.L.; Ponçano, W.L.; Campanha, G.A.C.; Nagata, N.; Almeida, M.A.; Stein, D.P.; Melo, M.S.; Cremonini, O.A. 1981. Mapa geológico do Estado de São Paulo. Escala 1:500.000. São Paulo, SICCT. v.1, 126p.

Brandt Neto, M.; Petri, S.; Coimbra, A.M. 1978. Considerações sobre a estratigrafía e ambiente de sedimentação da Formação Bauru. In: CONGRESSO BRASILEIRO DE GEOLOGIA, 30, Recife, 1978 Anais... Recife, SBG. v.2, p.1.557-566.

Campanha, G.A.C.; Carneiro, C.D.R.; Pereira JR., G.G.; Furumoto, S.; Hasui, Y.; Nagata, N. 1986. Uso do programa TRADE para determinação de direções principais de esforços pelos métodos Arthaud e Angelier. In: Carneiro, C.D.R. coord. Projeção estereográfica para análise de estruturas. São Paulo, UNICAMP/CPRM/IPT. p.115-120.

Caputo, R. 1995. Evolution of orthogonal sets of coeval extension joints. Terra Nova, 7:479-490.

Chang, H.K.; Kowsaman, R.O.; Bender, A.A.; Mello, U.T. 1990. Origem e evolução termomecânica de bacias sedimentares. In: GABAGLIA G.P.R. \& MILANI, E.J. coords. Origem e evolução de bacias sedimentares. Rio de Janeiro, Petrobrás. p.49-71.

Coimbra, A.M. 1976. Arenitos da Formação Bauru: estudo de áreas fonte. São Paulo, 2v. (Dissertação de Mestrado, Instituto de Geociências da Universidade de São Paulo).

Coimbra, A.M. 1991. Sistematização crítica da obra. São Paulo, 54p. (Tese de Livre-docência, Instituto de Geociências da Universidade de São Paulo).

Coimbra, A.M. \& Fernandes, L.A. 1994. A paleogeografia da Bacia Bauru (Cretáceo Superior, Brasil). In: CONGRESO ARGENTINO DE PALEONTOLOGIA Y BIOESTRATIGRAFIA, 6, Trelew, 1994. Actas... Trelew, Museo Paleontologia) Egidio Feruglio. p.85-90.

Coimbra, A.M.; Brandt Neto, M.; Petri, S. 1977.0 alinhamento estrutural do Tietê. In: SIMPÓSIO DE GEOLOGIA REGIONAL, 1, São Paulo, 1977. Atas.... São Paulo, SBG. p. 145-152.

Coimbra, A.M.; Brandt Neto, M.; Coutinho, J.M.V. 1981. Silicifícação dos arenitos da Formação Bauru no Estado de São Paulo. In: A FORMAÇÃO BAURU NO ESTADO DE SÃO PAULO E REGIÕES ADJACENTES, São Paulo, 1981. Coletânea de trabalhos e debates.. São Paulo, SBG. p.103-115.
Coimbra, A.M.; Fernandes, L.A.; Hachiro, J. 1992. Sismitos do Grupo Caiuá (Bacia Bauru, Ks) no Pontal do Paranapanema (SP). In: CONGRESSO BRASILEIRO DE GEOLOGIA, 37, São Paulo, 1992. Boletim de Resumos Expandidos.... São Paulo, SBG. v.2, p.503-504.

Coutinho, J.M.V.; Coimbra, A.M.; Brandt Neto, M.; Rocha, G. 1982. Lavas alcalinas analcimíticas associadas ao Grupo Bauru $(\mathrm{Kb})$ no Estado de São Paulo, Brasil. In: Congresso Latinoamericano de Geologia, 5, Buenos Aires, 1981. Actas... Buenos Aires, Servicio Geológico Nacional, v.2, p. 185-195.

Departamento de Águas e energia Elétrica (DAEE). 1976. Estudo de águas subterrâneas, regiões administrativas 7, 8, 9: Bauru, São José do Rio Preto, Araçatuba. São Paulo, DAEE. 4v.

Dunne, W.M. \& Hancock, P.L. 1994. Palaeostress analysis of small-scale brittle structures. In: Hancock, P.L. ed. Continental deformation. Oxford, Pergamon. p.101-120.

Engelder, T. 1987. Joints and shear fractures in rock. In: ATKINSON, B. ed. Fracture mechanics of rock. London, Academic Press, p.27-69.

Eyles, N. \& Eyles, C.H. 1993. Glacial geologic confirmation of an intraplate boundary in the Paraná Basin of Brazil. Geology, 21:459-462.

Fernandes, L.A. 1992. A cobertura cretácica suprabasáltica no Paraná e Pontal do Paranapanema (SP): os grupos Bauru e Caiuá. São Paulo, 129p. (Dissertação de Mestrado, Instituto de Geociências da Universidade de São Paulo).

Fernandes, L.A. \& Coimbra, A.M. 1992. A cobertura cretácea suprabasáltica no Estado do Paraná e Pontal do Paranapanema (SP): os grupos Bauru e Caiuá. In: CONGRESSO BRASILEIRO DE GEOLOGIA, 37, São Paulo, 1992. Boletim de Resumos Expandidos... São Paulo, SBG. v.2, p.506-508.

Fernandes, L.A. \& Coimbra, A.M. 1994. O Grupo Caiuá (Ks): revisão estratigráfica e contexto deposicional. Rev. Bras. Geoc., 24:164-176.

Fernandes, L.A. \& Coimbra, A.M. 1996. A Bacia Bauru (Cretáceo Superior, Brasil). An. Acad. Bras. Ci., 68:195-205.

Fernandes, L.A.; Coimbra, A.M.; Brandt Neto M. 1993. Silicifícação hidrotermal neocretácea na porção meridional da Bacia Bauru. Rev. IG, 14:19-26.

Ferreira, F. J F. 1982. Alinhamentos estruturais-magnéticos da região centro-oriental da Bacia do Paraná e seu significado tectônico. In: Geologia da Bacia do Paraná - reavaliação da potencialidade e prospectividade em hidrocarbonetos. São Paulo, Paulipetro Consórcio CESP/IPT. p. 143-166.

Fulfaro, V.J. 1974. Tectônica do alinhamento estrutural do Paranapanema. Boi IG-USP, 5:129-138

Fulfaro, V.J. \& Barcelos, J.H. 1993. Fase rifte na bacia sedimentar do Paraná: a Formação Caiuá. Geociências, 12:33-45.

Fulfaro, V.J. \& Perinotto, J.A.J. 1996. A Bacia Bauru: estado da arte. In: Dias-Brito, D.; Rohn, R.; Perinotto, J.A.J. eds. Boletim do $4^{a}$-Simpósio sobre o Cretáceo do Brasil. Águas de São Padro e Rio Claro, UNESP. p.297-303.

Fulfaro, V.J; Saad, A.R; Santos, MV; Vianna, R.B. 1982 Compartimentação e evolução tectônica da Bacia do Paraná. Rev. Bras. Geoc., 12:590-611.

Hachiro, J - Coutinho, JMV · Riccomini, C. Coimbra A.M. Fernandes, L.A. 1994. O Astroblema de Piratininga (São Paulo, Brasil). In: SIMPÓSIO SOBRE O CRETÁCEO DO BRASIL, 3, Rio Claro, 1994 Boletim... Rio Claro, UNESP. p.93-96.

Hancock, P.L. \& Engelder, T. 1989. Neotectonic joints. Geol. Soe. Am. Buli, 101:1.197-1.208.

Hasui, Y. 1969.0 Cretáceo do oeste mineiro. Bol Soe. Bras. Geol, 18:38-56.

Hasui, Y. \& Haralyi, N.L.E. 1991. Aspectos litoestruturais e geofísicos do soerguimento do Alto Paranaíba. Geociências, 10:57-77.

Hasui, Y.; Almeida, F.F.M.; Mioto, J.A.M.; Melo, M.S. 1982. Geologia, tectônica, geomorfologia e sismologia regionais de interesse às usinas nucleares da Praia de Itaorna. São Paulo, IPT S. A. 149p. (Monografia $\mathrm{n}^{\mathrm{0}}$ 7).

Instituto Geográfico e Geológico (IGG). 1974. Mapa Geológico do Estado de São Paulo, 1:1.000.000. São Paulo, IGG. 1 folha.

King, L.C. 1956. A geomorfologia do Brasil oriental. Rev. Bras. Geog., 18:147-265.

Magalhães, F.S.; Marques, J.D.; Serra JR., E. 1992. Análise estrutural do macico rochoso de fundação da Barragem de Porto Primavera, Rio Paraná (SP/MS). In: Hasui, Y. \& Mioto, J.A. coords. Geologia Estrutural Aplicada. São Paulo, ABGE/VOTORANTIM. p.297-311.

Northfleet, A.; Medeiros, R.A.; Muhlmann, H. 1969. Reavaliação dos dados geológicos da Bacia do Paraná. Boi Técn. Petrobrás, 12:291-346.

Pollard, D.D. \& Aydin, A. 1988. Progress in understanding jointing over the past century. Bull Geol Soe. Am., 100:1181-1204. 
Quintas, M.C.L. 1995. O embasamento da Bacia do Paraná: reconstrução geofisica de seu arcabouço. São Paulo, 213p. (Tese de Doutoramento, Instituto Astronômico e Geofísico da Universidade de São Paulo).

Renne, P.; Ernesto, M.; Pacca, I.G.; Coe, R.S.; Glen, J.M.; Prévot, M.; Perrin, M. 1992. The age of Paraná Floord Volcanism, rifting of Gondwanaland, and the Jurassic-Cretaceous boundary. Science, 258:975-979.

Riccomini, C. 1989.0 Rift Continental do Sudeste do Brasil. São Paulo, 256p. (Tese de Doutoramento, Instituto de Geociências da Universidade de São Paulo).

Riccomini, C. 1995a. Tectonismo gerador e deformador dos depósitos sedimentares pós-gondvânicos da porção centro-oriental do Estado de São Paulo e áreas vizinhas. São Paulo, 1OOp. (Tese de Livre-Docência, Instituto de Geociências da Universidade de São Paulo).

Riccomini, C. 1995b. Padrão de fraturamentos do Maciço Alcalino de Cananéia, Estado de São Paulo: relações com a tectônica mesozóico-cenozóica do sudeste do Brasil. Rev. Brás. Geoc., 25:79-84.

Riedel, W. 1929. Zur Mechanik, geologischer Brucherscheinungen. Ein, Beitrag zum Problemder"Fiederspalten". Zentralbl.f. Mineral., Geol., u. Paleont., 1929B:354-368.

Sadowski, G.R. 1984. Estado da arte do tema: geologia estrutural de grandes falhamentos. In: CONGRESSO BRASILEIRO DE GEOLOGIA, 33 Rio de Janeiro, 1984. Anais... Rio de Janeiro, SBG. v.4, p. 1.767-1.793.

Sadowski, G.R. \& Dias-Neto, C.M. 1981. O lineamento sismo-tectônico de Cabo Frio. Rev. Brás. Geoc., 11:209-212.

Santos, P.R.; Rodrigues, M.E.; Luz, O.T. 1980. A Estrutura de Piratininga: mapeamento geológico de detalhe. São Paulo, Paulipetro - Consórcio CESP/IPT, 17p. (Relatório RT-021/80).

Soares, P.C. \& Landim, P.M.B. 1976. Comparison between the tectonic evolution of the intracratonic and marginal basins in South Brazil. An. Acad. Brás. CL, 48(suplemento):313-324.
Soares, P.C.; Landim, P.M.B.; Fulfaro, V.J.; Sobreiro Neto, A.F. 1979 Ensaio de caracterização estratigráfica do cretáceo no Estado de São Paulo. In: SIMPÓSIO REGIONAL DE GEOLOGIA, 2, Rio Claro, 1979. Boletim de Resumos... Rio Claro, SBG. p.30-31.

Soares, P.C.; Landim, P.M.B.; Fulfaro, V.J.; Sobreiro Neto, A.F. 1980. Ensaio de caracterização do Cretáceo no Estado de São Paulo. Rev. Brás. Geoc., 10:177-185.

Souza JR., J.J. 1984. O Grupo Bauru na porção setentrional da bacia sedimentar do Paraná. In: CONGRESSO BRASILEIRO DE GEOLOGIA, 33, Rio de Janeiro, 1984. Anais... Rio de Janeiro, SBG. v.2, p.944-957.

Suguio, K. 1973. Formação Bauru: calcários e sedimentos detríticos associados. São Paulo, 2v. (Tese de Livre-Docência, Instituto de Geociências da Universidade de São Paulo).

Suguio, K.; Fulfaro, V.J.; Amaral, G.; Guidorzi, L.A. 1977. Comportamentos estratigráfico e estrutural da Formação Bauru nas regiões administrativas 7 (Bauru), 8 (São José do Rio Preto) e 9 (Araçatuba) no Estado de São Paulo. In: SIMPÓSIO DE GEOLOGIA REGIONAL, 1, São Paulo, 1977. Atas.... São Paulo, SBG. p.231-247.

Turner, S.; Regelous, M.; Kelley, S.; Hawkesworth, C.; Mantovani, M. 1994. Magmatism and continental break-up in the South Atlantic: high precision ${ }^{40} \mathrm{Ar}-{ }^{39} \mathrm{Ar}$ geochronology. Earth Planei. Sei. Lett. 124:333-348.

Van Everdingen, D. \& Van Gool, J. 1990. QuickPlot, plotting program for orientation data. Newfoundland, Department of Earth Sciences, Memorial University of Newfoundland.

Zalán, P.V.; Wolf, S.; Conceição, J.C.; Astolfi, A.M.; Vieira, I.S.; Appi, V.T.; Zanotto, O.A.; Marques, A. 1991. Tectonics and sedimentation of the Paraná Basin. In: Ulbrich, H.H.G.J. \& Rocha-Campos, A.C. ed. Gondwana Seven. São Paulo, Instituto de Geociências da Universidade de São Paulo, p.83-117.

Manuscrito A-852

Recebido em 20 de setembro de 1996

Revisão do autor em 08 de agosto de 1997 Revisão aceita em 10 de agosto de 1997 